\title{
MyD 88 Polymorphisms in Children Diagnosed with Sepsis
}

\author{
Sinem Sarı Gökay ${ }^{1}$, Rıza Dinçer Yıldızdaş², Mustafa Yılmaz ${ }^{1}$, Kıymet Aksoy ${ }^{3}$, Ali Erdinç Yalın ${ }^{3}$, \\ Yaşar Sertdemir ${ }^{4}$, Gülsüm Uçar ${ }^{5}$, Özden Özgür Horoz ${ }^{2}$, Fatma Derya Özduran ${ }^{1}$, Hayri Levent Y1lmaz

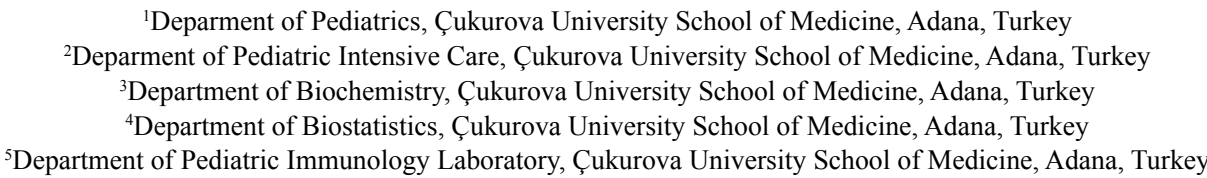

Background: Myeloid differentiation primary response gene 88 (MyD 88 ) is an intracellular adapter protein that mediates the early immune response to pathogens. Toll-like receptors (except TLR-3) induce the immune response through a MyD 88-dependent signal pathway.

Aims: We aimed to investigate the MyD 88 polymorphisms that play important roles in the immune response in septic children and to evaluate whether or not they were risk factors in the development of sepsis.

Study Design: Case-control study.

Methods: Sixty-five patients diagnosed with sepsis in the Pediatric Intensive Care Unit during the period from April 2010 to January 2012 were included as the study group. Sixty-five children without sepsis were included as controls. After DNA was obtained from blood samples in the study and control groups, MyD 88 polymorphisms were analyzed. According to the genotype and allele frequencies, the distributions of MyD 88 polymorphisms [Single nucleotide polymorphism (SNP) - 938 C/A (rs4988453), MyD 88 SNP $1944 \mathrm{C} / \mathrm{G}$ (rs4988457)] were analyzed in both the study and control groups.

Results: The C/C genotype of MyD 88 SNP -938 was significantly more common than the $\mathrm{C} / \mathrm{A}$ genotype in the patient group $(\mathrm{p}=0.002)$. No statistically significant difference in the frequency of the MyD 88 SNP 1944 genotype was found between the study and control groups $(\mathrm{p}=0.272)$.

Conclusion: Gene polymorphism studies could elucidate our understanding of sepsis in terms of prevalence and the managementof treatment. It was shown in this study that children with the MyD 88 SNP -938 $\mathrm{C} / \mathrm{C}$ genotype had a greater tendency toward sepsis. However, additional studies should be performed.

Keywords: Children, MyD 88 gene polymorphism, sepsis
Sepsis is a systemic inflammatory response syndrome against proven or suspected infection that should be diagnosed and treated in its early stages. Mortality is higher when diagnosis or treatment is delayed. Mortality rates has decreased by the improvements in antibiotic therapy, early diagnosis, improvements in intensive care and better understanding of the sepsis pathogenesis.
In recent years, the relationship between the severity of sepsis and septic shock and cytokine gene polymorphisms have garnered increasing attention. Also new researches showed genetic predisposition determines hosts susceptibility to infections (1). Studies in cytokine gene polymorphism [Tumor necrosis factor (TNF) receptors, IL-1 receptors] showed that mutations in Fc receptors, toll like receptors and mannose

This study has been presented as oral presentation at the 10 ${ }^{\text {th }}$ National Pediatric Emergency Medicine and Intensive Care Congress, 3-7 April 2013, Antalya, Turkey. Address for Correspondence: Dr. Sinem Sarı Gökay, Deparment of Pediatrics, Çukuruva University School of Medicine, Adana, Turkey 
binding protein caused severe pneumococcal and meningococcal infections and septic shock (1-3).

Toll like receptors form a family that includes at least 10 receptors and recognize specific molecular patterns derived from microorganisms, like bacterial cell wall components, carbohydrates and viral or bacterial nucleic acids (4). Activated toll like receptors phosphorylate protein kinases in cell and activate them. These biochemical reactions take place in cytosol and endosome. Some of these biochemical pathways are dependent on MyD 88 intermediary molecule and some are not. For example, inflammatory cytokines in sepsis and septic shock are released by MyD 88-dependent signal pathway (5). MyD 88 is an intracellular adapter protein that works in early immune response to pathogens. Toll like receptors (except TLR-3) induce immune response through MyD 88-dependent signal pathway. Bonnert et al. (6) in 1997 extracted and amplified human MyD 88 cDNA, which encodes a 296-amino acid polypeptide $(33 \mathrm{kDa})$. They showed in humans MyD 88 gene is located in chromosome 3p22-3p21.3 by using fluorescent in situ hybridization method. Medzhitov et al. (7) showed in humans MyD 88 is an adapter protein in toll like receptor signaling and this starts IRAK kinase, TRAP 6 protein and NFkB activation. According to Medzhitov et al. (7) MyD 88 is an general adapter and regulatory molecule for Toll/IL-1 receptor family in immune system. Researches showed MyD 88 deficient different mutations are detected in children who are more susceptible to bacterial infections (8).

We aimed to investigate the MyD 88 polymorphism, which plays an important role in the immune responses of septic children and to evaluate whether or not this polymorphism is a risk factor in the development of sepsis.

\section{MATERIALS AND METHODS}

This study was conducted during the period from April 2010 to January 2012. Before the study was performed, Ethic Committee approval is obtained. Patients who were diagnosed for sepsis in (PICU) are enrolled in this study. Patients who had malignancy and immunosuppressed patients were excluded. Control group constituted from healthy children that were never diagnosed for sepsis before. Oral and written informed consent was taken from the family of each patient included in this study.

The criteria and definitions used as the diagnostic criteria for sepsis in this study were obtained from the 2005 American College of Chest Physicians (ACCP), Society of Critical Care Medicine (SCCM), American Thoracic Society (ATS), European Society of Intensive Care Medicine (ESIC), the Surgical Infection Society (SIS), and the International Sepsis Definitions Conference (9).

\section{SNP genotyping}

For DNA isolation, blood samples were taken from patient and control groups in EDTA tubes and sent to the laboratory. High Pure PCR Template Kit (Roche; Basel, Switzerland) was used for DNA isolation. After DNA was extracted from patient and control group, genotyping for single nucleotide polymorphism in MyD 88 gene (GenBank Accession No: NM_002468) was studied using restriction fragment length polymorphism method (RFLP) after PCR amplification in Biochemistry Department. In our study, for each MyD88 polymorphism genotyping; MyD 88: SNP -938 (C>A) (dbSNP rs4988453, NM_002468.4:c.899C $>$ A) and MyD 88: SNP $1944(\mathrm{C}>\mathrm{G})(\mathrm{dbSNP}$ rs4988457, NM_002468.4:c.683+77C >G), PCR amplifications were carried out by using FastStart Taq DNA Polymerase (Roche; Catalog no: 04738357001500, Basel, Switzerland). The primers used for these polymorphism genotyping were as follows:

\section{MyD 88: SNP -938 (C $>$ A) (dbSNP rs4988453, NM_002468.4:c.-899C $>$ A)}

Forward Primer:

5'-GCAGCCAGGACCGCTTACTGCT-3'

Reverse Primer:

5'GCACGTGGCCTTGCCCTTGCCCTTTAGG-3'

MyD 88: SNP 1944 (C>G) (dbSNP rs4988457, NM_002468.4:c.683+77C $>$ G)

Forward Primer:

\section{5'- GCCCCAGCGACATCCAGTTTGTG-3'}

Reverse Primer:

5'- TCTTGCCAGAGCAGGGTTGAGCTT-3'

Amplification success was controlled by imaging PCR products after $1.5 \%$ agarose gel electrophoresis. Amplicons that were controlled by electrophoresis were digested by commercially available restriction endonuclease enzyme: BsrI at $65^{\circ} \mathrm{C}$ for MyD $88 \mathrm{SNP}-938(\mathrm{C}>\mathrm{A})$ and $\mathrm{Cac} 8 \mathrm{I}$ at $37^{\circ} \mathrm{C}$ for MyD 88 SNP $1944(C>G)$ for 16 hours. After 16-hour incubation, digested amplicons were separated by $3 \%$ agarose gel electrophoresis and the results were interpreted.

\section{Statistical analysis}

The Statistical Package Program for Social Sciences (SPSS) for Windows, version 19 (IBM Corp.; Armonk, NY, USA) was used for statistical analysis. Categorical measures were summarized as numbers and percentiles, numerical measures were summarized as means and standard deviations (as needed median or minimum-maximum). The genetic equilibrium was tested using the Hardy-Weinberg equilibrium. Chi-square test was used for nonparametric tests. Odds ratios and 95\% confidence intervals (CIs) were used to describe the distribution of the major risk factors. Statistical significance was accepted at the $\mathrm{p}<0.05$ level. 


\section{RESULTS}

Sixty-five patients who were diagnosed with sepsis and 65 healthy controls were included in this study. Mean age of the patients was 47.54 months (1-171 months), mean age of control group was 56.63 months (5-180 months). Two group were statistically insignificant $(\mathrm{p}=0.254)$. In the patient group, 38 were male $(58.5 \%), 27$ were female $(41.5 \%)$. In the control group, 35 were male (53.8\%), 27 were female (46.2\%) $(\mathrm{p}=0.724)$. In the patient group, 29 patients had sepsis (44.61 $\%), 24$ patients had severe sepsis (36.92\%), 12 patients had septic shock (18.47\%). In patient group, mean PIM II score was 43.53, mean PRISM II score was 19.82. In patient group, 34 patients $(52.3 \%)$ had a positive blood culture. In blood cultures, 12 patients had Gram (+) bacteria, 20 had Gram (-) bacteria and 2 had fungi. In the patient group, 15 patients died $(23.07 \%), 50$ patients were survived $(76.92 \%)$.

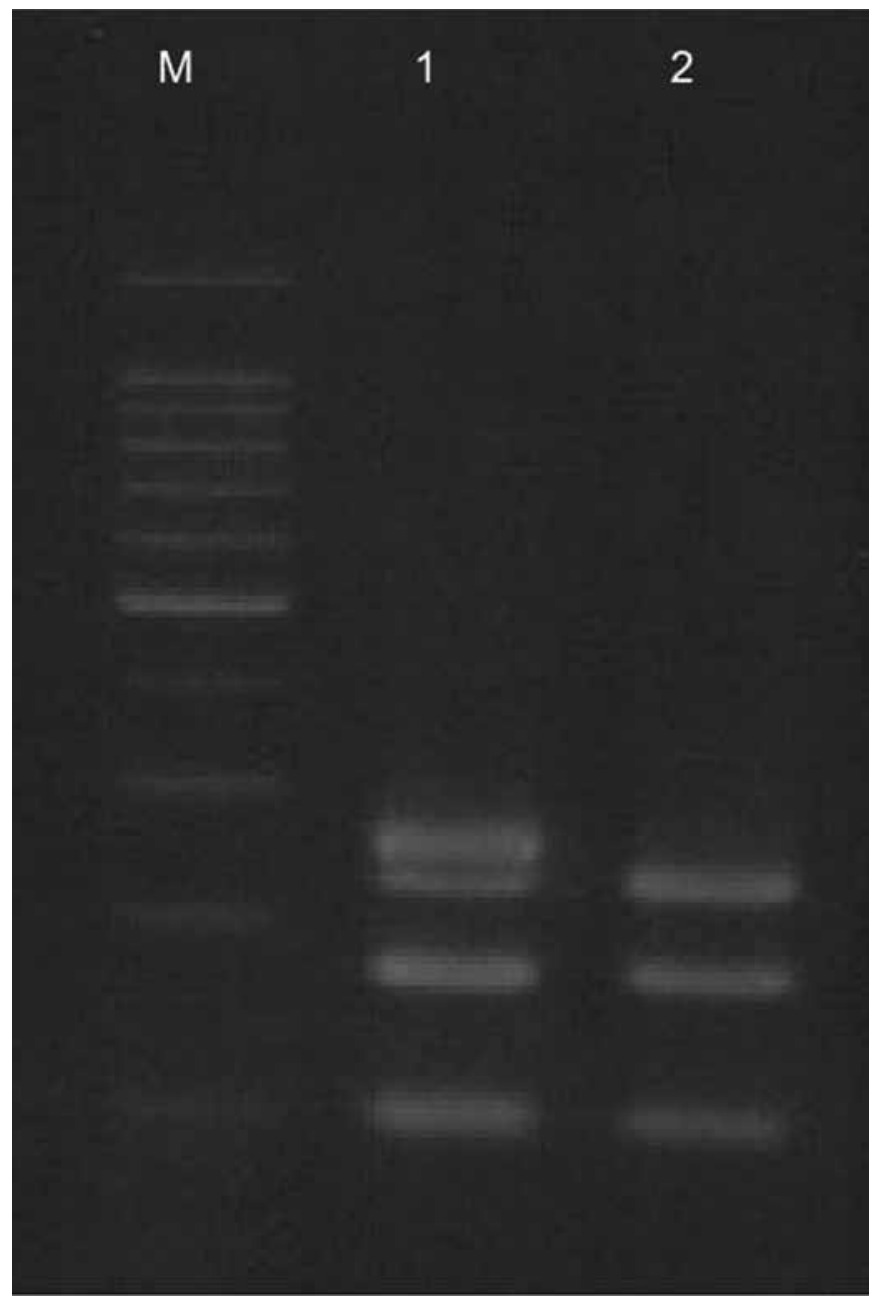

FIG. 1. 3\% agarose gel view of RFLP results for MYD 88 SNP-938 (dbSNP rs4988453, NM_002468.4:c.-899C $>$ A) polymorphism M: 100bp DNA Ladder; 1 : C/A; $2: \mathrm{C} / \mathrm{C}$
In the patient group, 10 patients had the MyD 88 SNP -938 C/A genotype (15.4\%), and 55 patients had the $\mathrm{C} / \mathrm{C}$ genotype (84.6\%). In the control group, 27 cases had MyD 88 SNP-938 C/A genotype (41.54\%) and 38 had C/C genotype (58.46\%). In MyD 88 SNP-938 patient group; 120 had C allele frequency (92.3\%), 10 had A allele frequency (7.7\%). In MyD 88 SNP938 control group; 103 had $\mathrm{C}$ allele frequency (79.23\%), 27 had A allele frequency (20.77\%). Patient and control groups were statistically significant based on MyD 88 SNP-938 genotype ( $\mathrm{p}=0.002)$. MyD $88 \mathrm{SNP}-938 \mathrm{C} / \mathrm{C}$ genotype was more frequent than C/A genotype in patient group. RFLP results for MyD 88 SNP-938 (rs4988453) polymorphism point by 3\% agarose gel electrophoresis are shown in Figure 1.

In the patient group, 10 patients had the MyD 88 SNP 1944 $\mathrm{C} / \mathrm{G}$ genotype (15.4\%) and 55 had the $\mathrm{C} / \mathrm{C}$ genotype (84.6\%). In the control group, 5 cases had MyD 88 SNP 1944 C/G genotype (7.69\%) and 60 had C/C genotype (92.31\%) (Table 1). In MyD 88 SNP 1944 patient group; 120 had C allele frequency (92.3\%), 10 had G allele frequency (7.7\%). In MyD 88 SNP 1944 control group; 125 had C allele frequency (96.15\%), 5 had $\mathrm{G}$ allele frequency (3.85\%). Patient and control groups were statistically insignificant based on MyD 88 SNP 1944 genotype ( $\mathrm{p}=0.272$ ). RFLP results for MyD 88 SNP 1944 (rs4988457) polymorphism point by $3 \%$ agarose gel electrophoresis are shown in Figure 2.

Among 93 cases with the MyD 88 SNP -938 C/C genotype, 27 had sepsis (29\%), 19 had severe sepsis (20.4\%), 9 had septic shock (9.7\%) and 38 were in the control group (40.9\%). Among 37 cases with the MyD 88 SNP -938 C/A genotype, 2 had sepsis $(5.4 \%), 5$ had severe sepsis $(13.5 \%), 3$ had septic shock (8.1\%) and 27 were in control group (73\%). MyD 88 SNP $-938 \mathrm{C} / \mathrm{C}$ genotype was more frequent in sepsis group and it was statistically significant $(\mathrm{p}=0.002)$.

Among 115 cases with the MyD 88 SNP 1944 C/C genotype, 27 had sepsis (23.5\%), 19 had severe sepsis (16.5\%), 9 had septic shock (7.8\%), and 60 were in the control group (52.2\%). Among 15 cases with the MyD 88 SNP 1944 C/G genotype, 2 had sepsis (13.3\%), 5 had severe sepsis (33.3\%), 3 had septic shock (20\%) and 5 were in control group (33.3\%) (Table 2). These findings were statistically insignificant $(\mathrm{p}=0.164)$.

Twenty nine patients had a positive blood culture out of 55 patients with the MyD 88 SNP -938 C/C genotype. 16 of them had Gram (-) bacteria (55.1\%), 11 had Gram (+) bacteria $(37.9 \%)$ and 2 had fungi (6.89\%). 5 patients had a positive blood culture out of 10 patients with the MyD 88 SNP -938 C/A genotype. 4 of them had Gram (-) bacteria ( $80 \%$ ) and one had Gram (+) bacteria (20\%). Relationship between MyD 88 SNP -938 genotype and gram staining of microorganisms was statistically insignificant $(\mathrm{p}=0.103)$. 
TABLE 1. Genotype and allele of frequencies of MyD 88 polymorphisms in sepsis and control group

\begin{tabular}{|c|c|c|c|c|c|c|}
\hline & & Patient $\mathrm{n}(\%)$ & Control n ( \% ) & $95 \% \mathrm{CI}$ & OR & $\mathrm{p}$ \\
\hline \multirow{6}{*}{ MyD 88 SNP -938 } & Genotype & & & & & \multirow{6}{*}{0.002} \\
\hline & $\mathrm{C} / \mathrm{C}$ & $55(84.6)$ & $38(58.46)$ & $1.69-9.00$ & 3.89 & \\
\hline & $\mathrm{C} / \mathrm{A}$ & $10(15.4)$ & $27(41.54)$ & $0.11-0.58$ & 0.25 & \\
\hline & ALLELE & & & & & \\
\hline & $\mathrm{C}$ & $120(92.3)$ & $103(79.23)$ & $1.45-6.80$ & 3.13 & \\
\hline & A & $10(7.7)$ & 27 (20.77) & $0.14-0.68$ & 0.31 & \\
\hline \multirow{6}{*}{ MyD 88 SNP - 1944} & GENOTY & & & & & \multirow{6}{*}{0.272} \\
\hline & $\mathrm{C} / \mathrm{C}$ & $55(84.6)$ & $60(92.31)$ & $0.14-1.42$ & 0.45 & \\
\hline & $\mathrm{C} / \mathrm{G}$ & $10(15.4)$ & $5(7.69)$ & $0.70-6.78$ & 2.19 & \\
\hline & ALLELE & & & & & \\
\hline & $\mathrm{C}$ & $120(92.3)$ & $125(96.15)$ & $0.15-1.44$ & 0.48 & \\
\hline & $\mathrm{G}$ & $10(7.7)$ & $5(3.85)$ & $0.69-6.27$ & 2.08 & \\
\hline
\end{tabular}

CI: confidence interval; OR: odds ratio; MYD 88: myeloid differentiation primary response gene 88; SNP: single nucleotide polymorphism

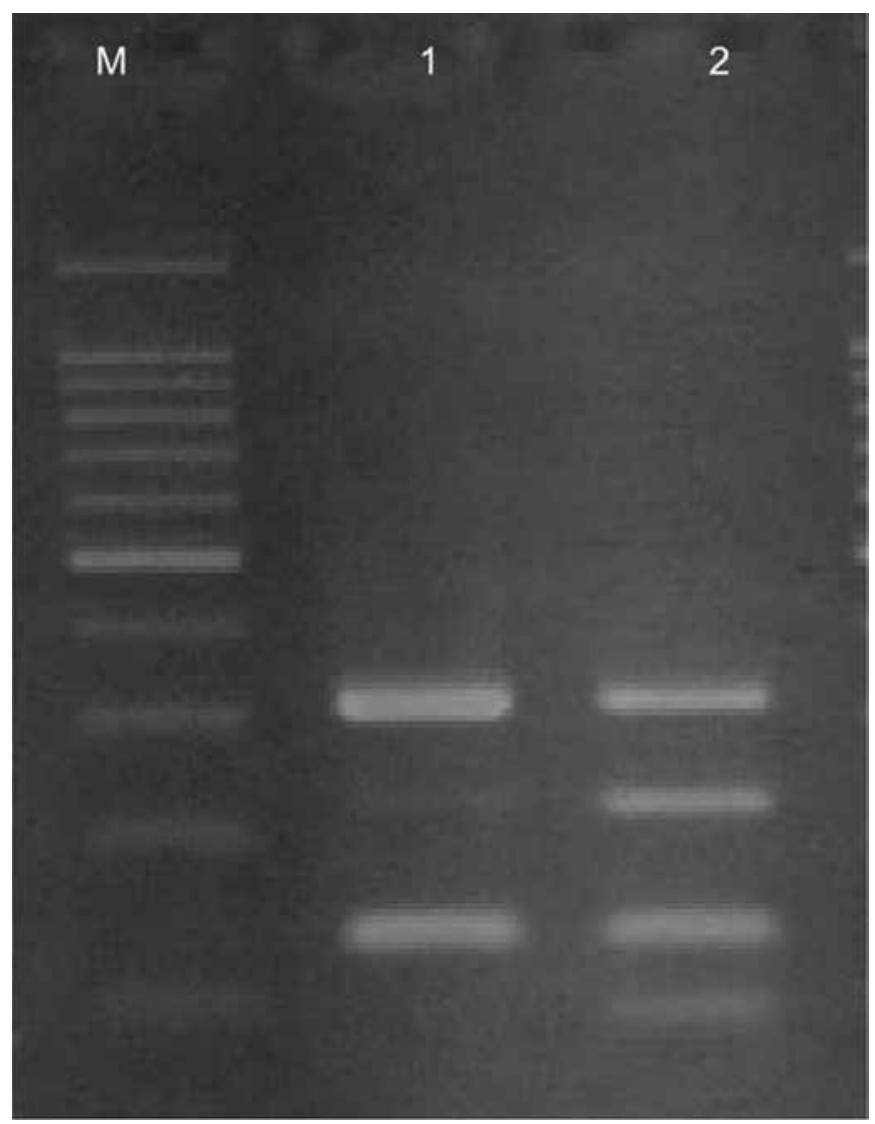

FIG. 2. 3\% agarose gel view of RFLP results for MyD 88 SNP-1944 (dbSNP rs4988457, NM_002468.4:c.683+77C >G) polymorphism M: 100bp DNA Ladder; $1: \mathrm{C} / \mathrm{C} ; 2: \mathrm{C} / \mathrm{G}$

Twenty nine patients had a positive blood culture out of 55 patients with the MyD 88 SNP 1944 C/C genotype. 16 of them had Gram (-) bacteria (55.1\%), 11 had Gram (+) bacteria $(37.9 \%)$ and 2 had fungi $(6.89 \%) .5$ patients had a positive
TABLE 2. Diagnosis percentiles based on genotypes

\begin{tabular}{lcccccc}
\hline & & $\begin{array}{c}\text { Severe } \\
\text { Sepsis } \\
\text { MyD 88 SNP }\end{array}$ & $\begin{array}{c}\text { Septic } \\
\text { Genotype }\end{array}$ & $\begin{array}{c}\text { Control } \\
\mathrm{n}(\%)\end{array}$ & $\begin{array}{c}\text { n (\%) } \\
\mathrm{n}(\%)\end{array}$ & $\mathrm{p}$ \\
\hline MyD 88 & $\mathrm{C} / \mathrm{C}$ & $27(29)$ & $19(20.4)$ & $9(9.7)$ & $38(40.9)$ & 0.002 \\
SNP -938 & $\mathrm{C} / \mathrm{A}$ & $2(5.4)$ & $5(13.5)$ & $3(8.1)$ & $27(73)$ & \\
\hline MyD 88 & $\mathrm{C} / \mathrm{C}$ & $27(23.5)$ & $19(16.5)$ & $9(7.8)$ & $60(52.2)$ & 0.164 \\
SNP - 1944 & $\mathrm{C} / \mathrm{G}$ & $2(13.3)$ & $5(33.3)$ & $3(20)$ & $5(33.3)$ & \\
\hline
\end{tabular}

MYD 88: myeloid differentiation primary response gene 88; SNP: single nucleotide polymorphism

blood culture out of 10 patients with the MyD 88 SNP 1944 $\mathrm{C} / \mathrm{G}$ genotype. Four of them had Gram (-) bacteria (80\%) and one had Gram (+) bacteria (20\%). Relationship between MyD 88 SNP -938 genotype and species of microorganisms was statistically insignificant $(\mathrm{p}=0.588)$.

Eleven patients out of 93 cases with the MyD 88 SNP -938 $\mathrm{C} / \mathrm{C}$ genotype $(11.82 \%)$ died $(\mathrm{p}=1.0)$. Four patients out of 37 cases who had MyD 88 SNP -938 C/A genotype (10.8\%) died $(\mathrm{p}=1.0)$. Four patients out of 15 cases who had MyD 88 SNP $1944 \mathrm{C} / \mathrm{G}$ genotype $(26.6 \%)$ died $(\mathrm{p}=0.073)$. Eleven patients died out of 115 cases who had the MyD 88 SNP 1944 C/C genotype $(9.56 \%)$ died $(\mathrm{p}=0.073)$. The relationship between the MyD 88 genotype and mortality was statistically insignificant.

\section{DISCUSSION}

Sepsis is a systemic inflammatory response syndrome against proven or suspected infection that should be diagnosed and treated in its earliest stages. Mortality is higher when di- 
agnosis or treatment is delayed. Mortality rates has decreased by the improvements in antibiotic therapy, early diagnosis, improvements in intensive care and better understanding of the sepsis pathogenesis.

Literature on MyD 88 SNP and sepsis relationship in human is limited. Song et al. (10) showed that gene variations of TLR signaling pathways and negative regulators of these pathways increase susceptibility to sepsis. That study was conducted between February 2006 and November 2009, in China. SNP was studied in 378 severe sepsis patients and 390 control cases. MyD 88 SNP allele and genotypes were found statistically insignificant between two groups. As a result, Song et al. (10) showed that MyD 88 SNP was not a risk factor for sepsis in China population. Von Bernuth et al. (8) discovered 3 different mutations in MyD 88 deficient children who are susceptible to pyogenic bacterial infections. They concluded that MyD deficiency was related to impaired cytokine response to TLR stimulation. Also, they proved MyD 88 deficient patients were susceptible to only Staphylococcus aureus, Pseudomonas aeruginosa and Streptococcus pneumonia infections and showed normal immunity to other infections (8).

In our study, 10 patients had the MyD 88 SNP $-938 \mathrm{C} / \mathrm{A}$ genotype (15.4\%); 55 patients had the $\mathrm{C} / \mathrm{C}$ genotype (84.6\%); in the control group, 27 cases had the MyD 88 SNP $-938 \mathrm{C} / \mathrm{A}$ genotype (41.54\%); 38 cases had the $\mathrm{C} / \mathrm{C}$ genotype (58.46\%). In the patient group, MyD $88 \mathrm{SNP}-938 \mathrm{C} / \mathrm{C}$ genotype was more frequent than $\mathrm{C} / \mathrm{A}$ genotype $(\mathrm{p}=0.002)$. We concluded that MyD 88 SNP -938 C/C genotype was a risk factor for sepsis. We discovered MyD 88 SNP 1944 C/C or C/G genotype were not risk factors for sepsis. Von Bernuth et al. (8) studied 12 MyD 88 deficient patients. 7 were male and 5 were female. 3 patients were newly diagnosed. 2 patients were 11 and 17 years old. The others were between 5 months and 8 years old. One patient was Turkish, 2 were French, 5 were Spanish, 2 were Portuguese and one was Serbian. Total invasive bacterial episode in patients were 33, for each patient it was between 1 and 7 episodes. Among these episodes; 17 were meningitis, 4 were sepsis, 6 were arthritis, 2 were osteomyelitis and 4 were intraabdominal or soft tissue abscess. In MyD 88 deficient patients; among noninvasive bacterial infections 5 were adenitis, 2 were sinusitis, 2 were recurrent otitis media, one was gingivitis and periodontal diseases and 2 were pneumonia. In both invasive and noninvasive bacterial infections, frequently Staphylococcus aureus, Pseudomonas aeruginosa and Streptococcus pneumonia were isolated. Patients had their first bacterial infections usually before 6 months old. 6 out of 12 patients died (11). Plantinga et al. (12) investigated relationship between candidemia and MyD 88 SNP. Patients who had one or more positive blood culture for Candida are included in this study. Immunosuppressed patients and patients who had malignancies, chemotherapy or organ transplantation were also included in this study. MyD 88 SNP (rs 4988453, rs 6853) was studied. They showed no relationship between candidemia and MyD 88 SNP (12). In our study, relationship between MyD 88 SNP -938 or MyD 88 SNP 1944 and species of microorganisms was statistically insignificant ( $\mathrm{p}>0.05)$.

In conclusion, we discovered that the MyD 88 SNP -938 $\mathrm{C} / \mathrm{C}$ genotype led to increased susceptibility to sepsis. We think that further research in this area should be conducted with larger patient populations. Further research into gene polymorphisms may be beneficial for gene therapy for sepsis.

Ethics Committee Approval: Ethics committee approval was received for this study from the ethics committee of Çukurova University School of Medicine.

\section{Informed Consent: N/A.}

Peer-review: Externally peer-reviewed.

Author contributions: Concept - S.S.G.; Design - S.S.G., R.D.Y.; Supervision - R.D.Y., M.Y.; Resource - R.D.Y., M.Y.; Materials - K.A., A.E.Y., G.U.; Data Collection and/or Processing - A.E.Y.; Analysis and/or Interpretation - Y.S.; Literature Search - Ö.Ö.H.; Writing - S.S.G., R.D.Y., F.D.B., H.L.Y.; Critical Reviews - R.D.Y., M.Y., H.L.Y., Ö.Ö.H.

Conflict of Interest: No conflict of interest was declared by the authors.

Financial Disclosure: This study was supported by the Çukurova University Research Fund (Project No: TF2010LTP25).

\section{REFERENCES}

1. Somec R, Amaglio N, Spirer and Rechavi G. Genetic predisposition to infectious pathogenes; a review of Iess familiar variants. Pediatr Infect Dis J 2003;22:457-61. [CrossRef]

2. Emonts M, Hazelzet JA, de Groot R, Hermans PW. Host genetic determinants of Neisseria meningitidis infection. Lancet Infect Dis 2003;3:565-77. [CrossRef]

3. Hubacek JA, Stüber F, Frohlich D, Book M, Wetegrove S, Ritter $\mathrm{M}$, et al. Gene variants of the bactericidal/permeability increasing protein and lipopolysaccharide binding protein in sepsis patients: Gender-specific genetic predisposition to sepsis. Crit Care Med 2001;29:557-61. [CrossRef]

4. Takeda K, Yamamoto M, Honda K. Assessing the response of cells to TLR stimulation. In: Konat GW, editor. Signaling by Toll-like Receptors. 1st edition. Boca Raton: CRC Press; 2008;1-22.

5. Takeda K, Kaisho T, Akira S. Toll-like receptors. Annu Rev Immunol 2003;21:335-76. [CrossRef] 
6. Bonnert TP, Garka KE, Parnet P, Sonoda G, Testa JR, Sims JE. The cloning and characterization of human MyD88: a member of an IL-1 receptor related family. FEBS Lett 1997;402:81-4. [CrossRef]

7. Medzhitov R, Preston-Hurlburt P, Kopp E, Stadlen A, Chen C, Ghosh S, et al. MyD88 is an adaptor protein in the hToll/Il-1 receptor family signaling pathways. Mol Cell 1998;2:253-8. [CrossRef]

8. von Bernuth H, Picard C, Jin Z, Pankla R, Xiao H, Ku CL, et al. Pyogenic bacterial infections in humans with MyD88 deficiency. Science 2008;321:691-6. [CrossRef]

9. Goldstein B, Giroir B, Randolph A. International pediatric sepsis consensus conference: definitions for sepsis and organ dysfunction in pediatrics. Pediatr Crit Care Med 2005;6:2-8. [CrossRef]

10. Song Z, Yin J, Yao C, Sun Z, Shao M, Zhang Y, et al. Variants in the Toll-interacting protein gene are associated with susceptibility to sepsis in the Chinese Han population. Crit Care 2011;15:R12. [CrossRef]

11. Picard C, Von Bernuth H, Ghandil P, Chrabieh M, Levy O, Arkwright $\mathrm{PD}$, et al. Clinical features and outcome of patients with IRAK-4 and MyD88 deficiency. Medicine (Baltimore) 2010;89:403-25. [CrossRef]

12. Plantinga TS, Johnson MD, Scott WK, Van de Vosse E, Velez Edwards DR, Smith PB, et al. Toll-like receptor 1 polymorphisms increase susceptibility to candidemia. J Infect Dis 2012;205:934-43. [CrossRef] 